\section{SOI: $1.1 /$ TAS DOI: $10.15863 /$ TAS International Scientific Journal Theoretical \& Applied Science}

\author{
p-ISSN: 2308-4944 (print) e-ISSN: 2409-0085 (online) \\ Year: $2016 \quad$ Issue: 12 Volume: 44
}

Published: $30.12 .2016 \quad \underline{\text { http://T-Science.org }}$

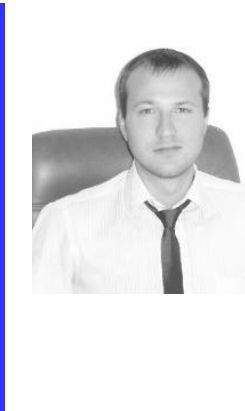

Oleksandr V. Stovpets $\mathrm{PhD}$ in Philosophy, Doctoral applicant, Philosophy, Sociology \& Sociocultural activities management department, South Ukrainian National Pedagogical University named after K. D. Ushynsky, associate professor of Odessa National Maritime University, Faculty of Law orcid.org/0000-0001-8001-4223 a.stovpets@gmail.com

SECTION 30. Philosophy.

\title{
PREMODERN AND MODERN: PROLEGOMENON TO THE DESIGNATION OF POSTMODERNITY IN THE CONTEXT OF RESEARCH FOR INTELLECTUAL PROPERTY INSTITUTION
}

\begin{abstract}
The article is dedicated to the reflection on paradigmal changes in the world cultural process, on their influence upon the Intellectual Property institution. This research analyzes social-philosophic aspects for development of the Intellectual Property Institution as a specific social institution that exists and functions in changing sociocultural conditions. There was particularly made an attempt to reconsider the meaning and character of those transformations in the field of intellectual property, also taking into account the Information Society context and realities of Postmodern cultural shift, including nonclassical \& post-nonclassical approaches.

The relevance and actuality of selected problematic is determined by the increasing significance of intellectual property institution that becomes an inalienable sociocultural attribute of post-industrial society. A socialphilosophic view of abovementioned problem involves the studying of Traditionalism, Modernism, Modern, Postmodernism phenomena as they unfold in a social sphere, creating a special context for various social institutions' existence and functioning.

As we may conclude, we should seek out the roots of so-called Postmodern-situation (that obviously leads to the coming of Postmodernity Age) within previous cultural-historical epochs. Therefore we suppose that Premodernity (i.e. Traditionalism, including the Antiquity, the Middle Ages, the Renaissance) and Modernity (that involves the Modern history \& the Contemporary history) are prolegomenon to Postmodernity. The last one is evaluated as the most probable sociocultural matrix in which the Intellectual Property institution will be going through changes, such as liberalization, diversification, growth of polymorphism \& eclecticism etc.
\end{abstract}

Key words: Intellectual Property, Postmodernity, Modern, Traditionalism, Knowledge, Information, Society, Social institutions, Philosophy.

Language: Russian

Citation: Stovpets OV (2016) PREMODERN AND MODERN: PROLEGOMENON TO THE DESIGNATION OF POSTMODERNITY IN THE CONTEXT OF RESEARCH FOR INTELLECTUAL PROPERTY INSTITUTION. ISJ Theoretical \& Applied Science, 12 (44): 115-123.

Soi: http://s-o-i.org/1.1/TAS-12-44-22 Doi: crossef http://dx.doi.org/10.15863/TAS.2016.12.44.22

\section{ПРЕМОДЕРН И МОДЕРН: ОБОЗНАЧЕНИЕ ПРОЛЕГОМЕНОВ К ПОСТМОДЕРНУ В КОНТЕКСТЕ ИССЛЕДОВАНИЯ ИНСТИТУТА ИНТЕЛЛЕКТУАЛЬНОЙ СОБСТВЕННОСТИ}

Аннотация: Статья посвящена отражению парадигмальных изменений в мировом культурном процессе, и их влиянии на институт интеллектуальной собственности. Данное исследование анализирует социально-философские аспекты развития института интеллектуальной собственности как специифического социального института, который существует и функционирует в изменяющихся соичиокультурных условиях. Особо была предпринята попытка пересмотреть смысл и характер тех преобразований в области интеллектуальной собственности, а также принимая во внимание Информационное общество, контекст и реалии постмодерна, культурный сдвиг, включая неклассический и пост-неклассический подходы.

Значимость и актуальность выбранной проблемы определяется ростом значения института интеллектуальной собственности, которая становится неотъемлемым соииокультурным атрибутом постиндустриального общества. Социально-философские представления указанных проблем предполагает 
изучение Традиционализма, модернизма, Модерна, постмодернизм явлений, как они разворачиваются в соичильной сфере, создания специального контекста для различных социальных институтов.

Как мы можем сделать вывод, мы должны искать корни так называемого постмодерна-ситуации (что, очевидно, приводит к пришествие постмодерна Возраст) в течение предыдущих культурноисторических эпох. Поэтому мы предполагаем, что Премодернизм (т.е. Традиционализм, включая античность, Средневековье, Ренессанс) и современность (что включает в современной истории и новейшей истории) являются пролегоменой к постмодерну. Последняя оценивается в качестве наиболее вероятной социокультурной матриць, в которой институт интеллектуальной собственности будет проходить через изменения, такие, как либерализация, диверсификация, рост полиморфизма, и эклектики u m.d.

Ключевые слова: Интеллектуальная собственность, Постмодерн, Модерн, Традиционализм, знания, информация, Общество, социиальные институть, Философия.

\section{Introduction}

Люди, принадлежащие к весьма разным параллельно сосуществующим обществам, могут жить в различное «культурное» и «философское» время с преобладанием разных социокультурных парадигм. Именно поэтому стратегию изучения изменений в институте интеллектуальной собственности, вероятно, следует строить с учётом трансформации социума по парадигмальной оси «премодерн - модерн постмодерн». Контемпоральность обществ, т.е. принадлежность людей к одному и тому же хронологическому моменту, их «коэкзистенция» на планете совсем не означает, что они живут в одном и том же социальном измерении. Об этом говорили ещё К. Маркс, вводя в дискурсивное поле термин «общественно-экономическая формация», и А. Тойнби с его цивилизационной теорией. Правда, известные феномены информатизации, глобализации, иные технологические и социальные факторы внесли (и продолжают привносить) свои коррективы в социо-культурную динамику исторического процесса.

\section{Materials and Methods}

В исследовании парадигмы постмодерна, прежде всего, как культурного контекста $и$ идеологического фона для существования интеллектуальной собственности, естественно, очень важным представляется понимание генезиса и смыслов постмодерна. Говоря о семантическом несовпадении физического (хронологического) и «социального» времени, мы также предполагаем, что постмодерн - категория, принадлежащая как раз к измерению «социального» времени. Постмодерн - это не только возможная грядущая эпоха, это свойство, которое структурно, содержательно, семантически зависит от той цивилизации, внутри которой протекает комплекс явлений, с реализацией которых связывают ситуацию постмодерна.

Многие исследователи, среди которых и А. Дугин, отмечают, что даже для авангардной части западной цивилизации постмодерн ещё по- настоящему не наступил, т.е. социум находится на стадии перехода из эпохи модерна в постмодерную эпоху. Поэтому, прежде чем говорить о постмодерне, а тем более - о процессах трансформации института интеллектуальной собственности в условиях постмодерна, мы приходим к необходимости сначала поговорить об эпохе модерна.

Без осмысления модерного концеетта, в орбите которого всё ещё пребывает значительная часть западной цивилизации и подавляющее большинство представителей других цивилизаций, бесполезно вести какие-либо разговоры об эпохе постмодерна. Исследование изменений в динамике развития общества модерна, по нашему убеждению, следует считать методологической платформой для любых попыток начать исследование ситуации постмодерна.

Вероятно, среди прочих определений, можно сказать, что модерн - это фаза социокультурного развития, наступившая после «премодерна». Для различных обществ модерн имеет разные временные параметры. Но именно из модерна и ведёт своё происхождение сама идея постмодерна. Эпоха модерна пришла на смену традиционализму в результате разложения феодального строя и утверждения капиталистического строя в Европе. Этот сложный и длительный социальный процесс сопровождался множеством событий, повлекших значительные социокультурные трансформации.

Переходу в модерн способствовали такие ключевые предпосылки, как Ренессанс (1416 ст.), Великие географические открытия (1516 ст.) и создание колониальных империй, Реформация (16-17 ст.) и её закономерный итог секуляризация; урбанизация, буржуазные перевороты (17-18 ст.) и переход к принципам парламентаризма; скачкообразные научная (1618 ст.) и промышленная революции (18-19 ст.) с последующей индустриализацией; крушение традиционных империй и строительство национальных государств, с новой институциональной системой и с иной идеологией (например, национализмом, который 
является частью программы модерна), и множество других факторов. Всё это происходило в европейской цивилизации в течение примерно 400 лет, и к началу XX века строительство модерна в Европе было завершено.

Т.е. модерн стал результатом начатой в XVI веке модернизации, символической точкой отсчёта которой можно назвать расширение географических горизонтов европейцев: открытие и новых торговых путей, и новых знаний об остальном мире (расширение культурной ойкумены). Сущностной же точкой отсчёта начала модернизации в Европе, вероятно, следует назвать Реформацию 16-17 ст, потому что именно с неё начинается развитие концепта нации, национального государства (со своей национальной церковью), бюргерства (и буржуазного класса как верхушки «третьего сословия»). Ведь Реформация привела не только к секуляризации и перераспределению церковной собственности в пользу буржуа. Она представляла собой нечто большее, чем трансформацию религиозного мировоззрения.

Реформация привнесла коренные изменения в социально-политическую и экономическую идеологию европейцев: создала предпосылки для развития гражданского общества, накопления капитала и развития промышленности, формирования т.н. протестантской этики (в итоге протестантские государства стали опережать в экономическом развитии и католические, и православные), способствовала повышению культурного и образовательного уровня населения. И хотя итоги реформационного движения сложно охарактеризовать однозначно, потому что ранее единая католическая Европа под духовным руководством папы римского была подвергнута религиозной децентрализации, всё же обозначенные выше процессы в своей совокупности способствовали смене феодальных экономических порядков на более прогрессивные - капиталистические.

Если ключевыми аспектами «премодерна» можно назвать средневековую идеологию (в частности, коллективизм, религиозность, идеализм), феодальную зависимость (и крепостное право как её основу), догматизм, иерархию сословного общества, аграрную основу хозяйствования, то общество эпохи модерна живёт совсем иными (нередко, прямо противоположными) категориями: буржуазная идеология (в частности, индивидуализм, прагматизм, секуляризм, материализм); идеи равенства возможностей, гуманизма и либерализма; протестантская этика; замена сословного общества классовым; капитализм, индустриализация, научный подход; переход от «циклического» времени к «линейно-осевому»; концепции прогресса и устойчивого развития.
Эта смена парадигм - из премодерна (традиционализма) в модерн (рационализм), достаточно ясно осмысленная европейскими интеллектуалами в эпоху Просвещения 17-18 вв., несомненно, стала тем фактором, что в дальнейшем позволил «западной цивилизации» сделать технологический, социальноэкономический и культурный рывок вперёд, и обеспечить себе глобальное стратегическое доминирование с середины XX столетия по сей день. Хотя концепт рационализма, наиболее расцветший в эпоху Просвещения и являющийся идеологическим базисом модерна, был в разной степени свойственен всему периоду Нового времени. Последний, конечно, очень обширен, и фактически наступил с социокультурной трансформацией европейской эстетики, которая в культурно-исторической терминологии обозначается как эпоха Возрождения, с её гуманизмом, обращением к античности и антропоцентризмом.

Модерн (будем употреблять данный термин условно, не имея ввиду одно лишь направление в искусстве Европы конца 19 ст.) - беспрецедентно ёмкая эпоха, длящаяся с периода Нового времени (около 15-19 вв.) до начала т.н. «четвёртой волны» информационной революции 1970-х, когда была изобретена микропроцессорная технология, сделавшая возможной изобретение в 1989 г. концепции Всемирной паутины в стенах CERN.

Модерну присущи такие знаковые явления и процессы, как социальная мобильность, автономия личности и эгоцентризм, экономический рост как показатель успеха, развитие институтов гражданского общества, государственный суверенитет, незыблемость частной собственности, коммерциализация творчества и рост массовой культуры, минимальный общеобязательный стандарт образования, свобода совести и огромное множество других понятий, вырастающих из концепции «прав человека». Перейдя из премодерна в модерн, человек западной цивилизации получает своего рода набор исходных культурных кодов, которые становятся определяющими для его развития. Он получает образование модерна, сознание модерна, язык модерна, технологии модерна, социальные практики и институты модерна.

Отдельно, в контексте исследования интеллектуальной собственности, хочется подчеркнуть значимость информационного фактора. Ведь «информаџионная эволющия» красной нитью проходит через всю цивилизованную историю, а принципиальные революционные - скачки, которые имели место в обозначенном эволюционном процессе, вошли в историю как «4 волны информационной 
революции»: 1) изобретение письменности, 2) изобретение книгопечатания, 3) изобретение электричества (телеграф, телефон) и радио, 4) изобретение искусственного спутника, микросхемы и виртуального пространства. Это технологическая закономерность, научно и технически обусловленная. Но повлияла она не только на производственные отношения, но и на творчество, как часть интеллектуального бытия.

Также следует отметить сложившуюся культурно-историческую закономерность в смене эпох: коренные социально-экономические перемены всегда находили отражение в сфере культуры (литературе, музыке, художественном искусстве, архитектурном облике городов и т.д.). Например, такое мощное культурноидеологическое течение в искусстве, как модернизм, предшествовало развитию стиля модерн в искусстве, и во многом послужило пролегоменом к концептуализации модерна (а позднее понятия «Модерн», «эпоха Модерна» стали отождествлять с понятием «Новое время», хотя эти градации весьма условны, а их временные рамки размыты). Как в своё время модернизм, будучи ранней ступенью авангардизма, обозначил начало пересмотра классических, премодерных традиций, так и теперь говорят о том, что постмодернизм - это начало пересмотра традиций модерна в культуре (что по той же логике должно вести к наступлению постмодерной эпохи).

Таким образом, в логике исторического развития культуры вырисовывается следующая последовательность: ПРЕМОДЕРН (это, говоря иначе, эра классической традиции: а) эпоха архаики - Античность, б) эпоха Средневековья, в) эпоха Возрождения) $\Rightarrow$ Модернизм (как избавление от пережитков традиционализма в модерне, получившее наиболее яркую манифестацию в сфере искусства и литературы) $\Rightarrow$ МОДЕРН (эра неклассической традиции в искусстве и философии, а также жизненная концепция, в которой сегодня пребывает огромная часть прогрессивного человечества) $=>$ Постмодернизм (как нынешний переход от неклассической традиции к постнеклассической; на этой стадии, как нам мыслится, находится сегодня лишь самая передовая часть западной цивилизации) => ПОСТМОДЕРН (возможный результат преодоления идеологии Модерна, но не «антимодерн»; это эра вероятного будущего, окутанная ныне неизвестностью; учитывая существующее множество противоречивых характеристик и самых разных изображений перспектив развития, связанных с эпохой постмодерна, пока что можно с уверенностью констатировать лишь одно очевидное свойство постмодерной концепции - неопределённость).
Неопределённость царит и в периодизации вышеобозначенных этапов развития культуры человечества (в частности, той его части, что подпадает под принятое обозначение «западная цивилизация»). Как уже говорилось, мы можем лишь условно отождествлять понятия «эпоха модерна» и «Новое время», и лишь условно определять временные рамки их наступления. Историки связывают наступление Нового времени не то с фактом свершившегося Ренессанса, не то с началом Реформации. Искусствоведы, культурологи и философы говорят, что модернизм и модерн (как образы мышления, и как совокупность направлений и стилей в искусстве конца XIX - начала XX вв.), начиная уже со второй половины XX века уступают место постмодернизму во всём многообразии его проявлений.

Следовательно, мы наблюдаем явное несовпадение между предполагаемым моментом наступления эпохи Нового времени около 16 века, и расцветом модерна (осознания его как стиля и идеологии) в конце 19 века. Вероятно, в таком контексте будет правомерно говорить лишь о том, что эпоха модерна полноценно обозначается в жизни западного общества в самый разгар того периода, который историки называют Новым временем. Завершение же проекта «модерн», крах его метанарративов (о котором так много сказано философамипостмодернистами) обусловлены мировыми войнами и системным культурным кризисом, а пик разочарования в модерных ценностях приходится уже на тот опять-таки условный период, который историки именуют Новейшим временем (Contemporary history).

Если ставить концепцию модерна на центральное место в культурной истории, тогда две другие социокультурные парадигмы, «премодерн» и «постмодерн», создаются для обозначения всего того, что «модерном» не является. При этом все «немодерные» явления распределяются по временной шкале «до модерна» и «после модерна». В этом утверждении нам близка позиция современного философа А. Дугина касательно определения места трёх обозначенных культурных матриц, т.е. их последовательного выстраивания по парадигмальной оси «премодерн - модерн постмодерн». Но большинство исследователей всё же не склонны говорить о большей или меньшей значимости каждой из этих культурных матриц, а лишь констатируют их наличие и последовательность.

В целом же, для привнесения относительной ясности в понимание хронологии смены этих трёх фундаментальных культурных парадигм, будем исходить из утвердившейся (в теории культуры, в философии истории, в социальной 
философии) схемы, прежде всего, применимой к «европейской цивилизации»: 1. Премодерн (традиционное общество); 2. Модерн (Новое время, Modern history, XVI-XX столетия, имея ввиду, что об окончательном формировании парадигмы модерна можно говорить с утверждением данной идеологии в искусстве, на рубеже XIX-XX столетий, а огромный массив социально-экономических, научных, технологических, политических предпосылок прихода модерна относится к гораздо более раннему периоду, начавшемуся около XVI века; неслучайно, что модернизм возникает как некий пик модерна в конце XIX столетия, как процесс очищения модерна от всех элементов премодерна); 3. Постмодерн (начало которому даёт идейное течение постмодернизма, возникшее во второй половине ХХ века и получившее продолжение в наши дни). Эти три типа общества определяются множеством нюансов, и обозначенные культурные матрицы распадаются на бесчисленное количество версий и вариаций. И для каждой из этих трёх фундаментальных социально-философских парадигм характерен свой специчфический тезаурус.

Основная идея «премодерна» - это тип общества, основанный на традиции, на религиозных принципах сакрального, сверхъестественного, с философией платонизма и аристотелизма. Именно в премодерную эпоху формируются все основные религиозные типы, древние культы, мировые религии. Премодерн это не только временное понятие, это концептуальное понятие. Всякий глубоко религиозный человек принадлежит к обществу премодерна. Его представители - это ортодоксальные носители иудаизма, индуизма, буддизма, христианства, ислама и всех прочих консервативных типов религиозного сознания. Новое время - модерн - отрицает ключевые пункты идеологии «старого времени». Премодерн утверждает «Бога», модерн - «Человека» (личность); премодерн утверждает трансцендентность, идеализм, креационизм, а модерн - имманентность, гилозоизм, разум, рассудок, науку, эксперимент, эволюционизм. Тезаурус постмодерна рассмотрим позднее.

Говорить о постмодерне может только то общество, которое выстроило проект модерна до конца, т.е. прошло весь путь модернизации, «очистило» всю свою культурную матрицу от элементов премодерна (от архаики, пережитков традиционализма), а позднее - ввиду известных катаклизмов - разочаровалось в идеалах модерна (тогда и произошёл тот самый «крах метанарративов»). И только находясь в точке «совершенного модерна», общество начинает задаваться вопросом: а что же дальше ?
А дальше (по крайней мере, у нас) возникает необходимость исследовать генезис самого понятия «постмодерн», дабы понять, что лежит в основе концепта постмодерна (и есть ли у него вообще концепт, или же можно говорить пока только о «ситуации» постмодерна).

Уже несколько десятилетий в философии, социологии, культурологии Западной Европы ведутся дискуссии о ситуации постмодерна, о явлении постмодернизма - о сути этих понятий, о времени их появления, о причинах, их породивших, об их отношениях с модерном и модернизмом. По многим из перечисленных вопросов единства нет. Попробуем, тем не менее, выделить те тенденции в культуре, на основе которых анализируется постмодерный концепт. При этом сделаем оговорку, что под «постмодернизмом» будем подразумевать реально существуюшую, актуальную и многоаспектную тенденцию в западной культуре второй половины XX - начала XXI века, которая нередко вступает в противоречие с идеологией эпох модерна и премодерна. Под «постмодерном» же будем иметь в виду потенциально грядущую культурноисторическую эпоху, которая с наибольшей степенью вероятности утвердится сначала в Западном мире, а затем будет стремиться к экспансии на остальное человечество. Иными словами, постмодернизм (как комплекс тенденций «западной современности») является своего рода пролегоменом к постмодерну, предваряет его наступление.

Понятия «постмодерн», «постмодернизм», «постмодерный» многозначны. Нередко их ошибочно отождествляют. Они используются и для обозначения своеобразного направления в современном искусстве, и для характеристики определённых тенденций в политике, религии, этике, образе жизни, мировосприятии, но также и для периодизации культуры и обозначения соответствующей философской концепции. А такие явления, как постиндустриализм, потребительское общество, массовая культура и некоторые другие являются, скорее, социальноэкономическими предпосылками для смены социокультурных парадигм. Так, большинство постмодерных феноменов возникло как специфическая реакция на устоявшиеся формы предшествующей культуры ведущих стран Европы и Америки. Однако, по мнению Х. Сильвермана [1], у постмодернизма нет родины.

Впервые понятие «постмодерн» в смысле, приближенном к сегодняшнему, употребил в 1946 г. А. Тойнби [2], обозначая определённый этап в развитии западноевропейской культуры, ознаменованный переходом от политики, опирающейся на мышление в категориях 
национальных государств, к политике, куда более учитывающей глобальный характер международных отношений. В. Вельш [3], исследуя генеалогию понятия «постмодерн», отмечает ряд случаев его «преждевременного» употребления: в 1917 году в книге немецкого философа-эссеиста Р. Паннвица «Кризис европейской культуры» [4], где речь идёт о «постмодерном человеке», сущность которого весьма неопределённа; в 1934 году у испанского литературоведа Ф. Ониса [5], где фиксируется совсем иное понимание - «постмодернизм» рассматривается как промежуточная фаза в развитии литературы между модернизмом и так называемым «ультрамодернизмом».

По меткому определению В. Вельша, поначалу слово «постмодерн» встречается спорадически: не прослеживается ни причинной взаимосвязи между употреблениями этого термина, ни содержательной. Да и области, где он появляется, весьма различны: то сфера общей культуры, то только литература, то политика. Хронология также колеблется: от чисто будущей перспективы до отнесения начала постмодерна к рубежу XIX и XX веков. И, наконец, оценки масштабов также расходятся весьма существенно: под постмодерном подразумевают то новую вершину развития культуры в стремлении преодолеть декаданс и нигилизм модерна, то короткую интермедию, то идеологическое явление в политике, то новейшую тенденцию в развитии массовой культуры. Т.е. приведенные ранее случаи свидетельствуют о неоднозначности трактовки понятия постмодерна, и только со временем оно начинает приобретать более ясные очертания, обрастая фиксированным смыслом.

Большинство постмодерных теоретиков, среди которых наиболее известны Р. Барт, Ж. Батай, Ж. Бодрийяр, Ж. Делёз, Ж. Деррида, Ф. Джеймисон, Ф. Гваттари, Ю. Кристева, Ж. Лакан, Ж.-Ф. Лиотар, М. Фуко, И. Хассан, У. Эко, склоняются к тому, что раньше всего в русле художественной культуры возник постмодернизм. Данное идейное течение изначально может быть отнесено, прежде всего, к таким областям, как литература, архитектура, кино, изобразительное искусство, музыка. Но в дальнейшем, под влиянием различных факторов - от развития постнеклассического типа философствования до интенсивной глобальной информатизации - постмодернизм постепенно распространился и на сферы политики, науки, философии, религии.

Достаточно обоснованным, учитывая специфику нашего исследования, будет начать рассмотрение постмодерной тематики со сферы творчества, в частности, литературы. Принято считать, что постмодернистское произведение адресуется одновременно и к «массе», и к «элите», т.е. к совершенно разным социальным группам. В отличие от культуры модернизма, постмодернизм способствует демократизации и диссеминации культуры, поискам новых ходов в творчестве (иногда, правда, на грани абсурда) и унификации социальных адресатов. По мнению М. Хайдеггера, это «снижение высших ценностей» [6] произошло не от желания слепого разрушения, не от страсти к обновленчеству, а от необходимости придать миру какой-то смысл.

Степень отказа от культуры модернизма разными исследователями видится по-разному. Резкое противопоставление модернизма постмодернизму характерно для У. Эко, который отмечает, что наступает момент, когда модернизму дальше некуда идти, так как он «разрушает образ, отменяет образ, доходит до абстракции, до чистого холста, до дырки в холсте. Вот почему постмодернизм возникает как ответ модернизму: раз уж прошлое невозможно уничтожить, ибо его уничтожение ведёт к немоте, его нужно переосмыслить, иронично, без наивности» [7]. У. Эко также вводит в теорию культуры и искусствоведения понятие, которое инициировало интерес к тексту и его интерпретации. Речь идёт о модели «открытого произведения», фиксирующей незавершённость произведений культуры, их открытость для разнообразных читательских интерпретаций [8; 9]. Именно двусмысленность, амбивалентность, неоднозначность возможных трактовок порождает дискуссии о современном статусе интеллектуальной собственности на фоне постмодерных тенденций.

Постмодернизм (как своего рода предтеча постмодерна) отторгает, прежде всего, модернистские ценности. Что же касается «классической» культуры (премодерна), то здесь налицо процесс переосмысления, заимствования, эксплуатации уже отработанных форм. Именно в этом ключе следует понимать появление таких новых приёмов в художественном творчестве, как «интертекстуальность», «нонселекция» и иных, которые сложились в постмодернистский период и нашли своё теоретическое обоснование у философов-постструктуралистов и культурологов Р. Барта, М. М. Бахтина, Ю. Кристевой, Ж.-Ф. Лиотара.

Идея использования прежних форм в художественном творчестве (поскольку всё уже было найдено, и всё применено) ставит художника, по мысли Ж.-Ф. Лиотара, в положение философа, изобретающего новые правила игры [10]. Именно эта способность современного художественного творчества использовать различные стили, жанры, сосуществование разных форм, дала основание В. Вельшу назвать искусство «школой

ISPC Generalization of scientific results, 
плюрализма», и выделить наиболее очевидные черты постмодернизма - плюрализм и эклектичность (гибридность).

Ещё одним из «опознавательных знаков» новой философии является её мифологичность. Классический рационализм, господствовавший в европейской философии вплоть до начала XX века, имел значительные недостатки: он страдал гносеологизмом, практически совсем игнорировал онтологию, был невнимателен к живому чувственному субъекту, отличался самонадеянностью автономной мысли и т.д. Но в одном ему нельзя было отказать - в умозрительном утверждении достоинства человека. Какая бы роль ни отводилась индивиду в системе Целого, всё же человек априори считался причастным к высшему, разумному, сознательному бытию. И само бытие, история, культура также считались сопричастными к некому высшему разумному смыслу.

Принципиально иное миропонимание было предложено с подменой разумного основания мира иным, отрицающим примат разума, например, некой иррациональной Волей (у А. Шопенгауэра), или заменой суверенного разума имморальным произволом субъекта волей к власти (у Ф. Ницше). И хотя А. Шопенгауэр полностью не отрицает И. Канта и ещё оперирует терминами философской классики, но по существу он бросает вызов всей предшествующей логике мышления. Его тёмная, бессознательная Воля выступает антагонистом традиционному философскому осмысляющему и просветляющему Разуму. По этой логике философ отказывается от своего изначального призвания, от традиционной задачи - отыскать и утвердить смысл существования и предельные основания бытия. История объявляется чуть ли не бесцельной и бессмысленной. Когда установка на понимание сменяется волевым отношением к миру, открывается неограниченная возможность всевозможных умозрительных манипуляций.

Если в прежние времена философская установка была связана с целями поиска истины, то теперь мыслитель ищет уже не столько истину о мироздании, но сюжет для собственного построения мироздания - как мотив, годный для произвольного обыгрывания. На место напряженного размышления о мире встаёт конструирующее, творящее воображение. Поэтому когда философ становится «автором», его познание становится изобретением, а философия - в какой-то степени «мифом». И пролог к этой новой эпохе «власти мифа» создал упомянутый ранее Ф. Ницше, когда провозгласил, в противовес «выродившейся» истине познания, притягательность и новую «истинность» мифа.
С одной стороны, мифологичность постмодерной философии обусловлена тем, что речь в ней идёт не о поисках истины (ведь истина теперь вариативна, относительна и т.д.). Как и любой миф, она нередко апеллирует к дорациональным или подсознательным всеобщим структурам. И, наконец, постмодерная философия мифологична постольку, поскольку предназначена для коллективного пользования: она объединяет довольно обширные социальные группы, конструирует субкультуры.

С другой стороны, постмодерная философия не является «мифом» в классическом понимании. Во-первых, нет всеобщей веры в непреложность «постмодерных истин». Во-вторых, тут нет и тени спонтанного коллективного творчества. Таким образом, речь идёт о мифе нового типа, нашедшем характерное отражение в творчестве О. Шпенглера, М. Хайдеггера, Й. Хёйзинги, 3. Фрейда, К. Юнга и других мыслителей XX столетия. Представители неклассического типа философствования выразили вполне правомерный протест против однобокости рационализма, против рационалистической гармонизации мира и панлогического усечения бытия. Однако философы постнеклассического поколения пошли гораздо дальше, порой пускаясь в настоящую войну против разума.

Если до сих пор истину пытались искать у разума, то теперь её стали усматривать в противоположном месте: в досознательном, бессознательном, подсознательном. На смену «философии мысли» пришла «философия жизни», которая оказалась основным руслом новейших культурфилософских идей. Эпоха «пост-», т.е. «время после» - это настоящее время, в котором возник новый способ осмысления реальности - постмодернизм, ставший за последние десятилетия признанным способом мышления.

Постмодернизм фиксирует ментальную специфику современной эпохи в целом. Постмодерная философия является своеобразным отражением фундаментальных сдвигов в современной культуре, поэтому знакомство с основными постмодерными идеями можно считать необходимым для более основательного понимания противоречивого мира, в котором развивается институт интеллектуальной собственности. Одной из особенностей постмодернизма является то, что созданные в его русле концепции не ограничиваются какой-либо одной отдельной областью реальности, а рассматривают многомерное бытие человека через призму сложной системы взаимосвязанных категорий: «психика» - «язык» - «знак» «коммуникация» - «социум» - «культура» «власть» - «ментальность». 
Оглядываясь на минувшее столетие, можно выделить своего рода «знаки времени», которыми оно было окрашено. Если начало политической истории XX века связывают с Первой мировой войной и всеми вытекающими из неё последствиями, то «интеллектуальная» история прошлого века началась с создания нового символа, который стал доминирующим уже в культуре XXI века. Этим символом стала «относительность», связанная, конечно же, с именем А. Эйнштейна, опубликовавшего в 1905 г. статью «К электродинамике движущихся тел», совершившую переворот в науке [11]. Специальная и общая «теория относительности» А. Эйнштейна реализовали в физике принцип, провозглашённый чуть ранее Ф. Ницше, который угрожал «моральным идолам Европы» пока ещё только «философским молотом» [12]. Моральный релятивизм, размывание границ добра и зла, относительность нравственных идеалов и принципов станет едва ли не главным знамением XX века.

Следующим знаком эпохи, отметившим первую половину ХХ столетия, были всевозможные рассуждения на тему «конца», некого предельного рубежа, обыгрываемые в различных вариациях как «смерть», «упадок», «закат», «сумерки», «финал», «декаданс». Это выражало определённый перелом в основных традициях западного философского мышления. Началом тематики «конца» была, прежде всего, «смерть Бога», провозглашённая Ф. Ницше. Во многом этот образ был навеян Первой мировой войной и установлением советской власти в России, разрушавшими этические устои старого буржуазного общества. Тематика «конца» многократно отразилась в философских произведениях и концепциях: «Сумерки идолов. Как философствуют молотом» (1888) Ф. Ницше, «Закат Западного мира» (1918) О. Шпенглера, «преодоление метафизики» у М. Хайдеггера, «смерть автора» у Р. Барта, «смерть субъекта» у М. Фуко, «конец истории» у Ф. Фукуямы, «конец философии» у Б. Рассела и Р. Рорти, - всё это отражает некий фундаментальный перелом в европейском самосознании.

Постмодернистское мировоззрение и мироощущение нашли своё наглядное воплощение в художественном творчестве. С одной стороны, искусство стало генератором многих постмодернистских идей, с другой же оно стало формой кодирования, трансляции и манифестации этих идей. Многие черты, присущие постмодернистскому искусству, не столько характеризуют его само, сколько выражают общую культурную парадигму современности.

Именно в этом ключе была изложена обобщающая классификация основных характеристик постмодернистского искусства, предложенная И. Хассаном [13] и выражающая, по его мнению, культурную модель современности. Взяв за основу его идею, мы предлагаем излагать постмодернистские черты в следующем сочетании: 1) неопределённость, открытость, незавершённость, неоднозначность; 2) фрагментарность, клиповость, эклектичность, тяготение к коллажам, к цитатам; 3) тяготение к деконструкции (к разрушению стереотипов, включению в новый контекст), деканонизация (отказ от традиционных канонов, безусловных авторитетов; карнавализация, маргинальность, порой на грани с абсурдом); 4) утрата «Я» и глубины, поверхностность, многовариантное толкование; 5) интерес к изотерическому, к пограничным ситуациям; 6) обращение к игре, к аллегории; 7) ироничность, пародийность, репродуцирование, имитации, обогащающие возможности репрезентации реальности; 8) антиутопичность, крах метанарративов; 9) перформанс, обращение к телесности, материальности; 10) сконструированность, с использованием иносказания, фигурального языка; 11) имманентность (в отличие от «премодерна», который стремился к прорыву в трансцендентное, постмодернистские искания направлены на человека, на внутренне присущее ему). Разумеется, этот «гибридный» список постмодернистских атрибутов не претендует ни на абсолютную истинность, ни на какую-либо завершённость или исчерпывающий характер. Он может быть дополнен либо же вообще кардинально пересмотрен. Конечно, подобная вариативность - тоже в духе постмодернизма.

\section{Conclusions}

Перемены в современном мире происходят с такой быстротой, что аналитики, в том числе и философы, за ними не всегда поспевают. А тем более отстают в их осмыслении законодатели. Сфера интеллектуальной собственности - не исключение. В течение как минимум шести последних столетий разрабатывалась сложная, многокомпонентная социальная (и в первую очередь, правовая) концепция интеллектуальной собственности. Развивалось общество, менялся облик цивилизации, и созданная правовая концепция переосмысливалась в отдельных отношениях.

Создаваемый веками социальный институт интеллектуальной собственности был вполне хорош в реалиях эпохи премодерна, и даже достаточно адаптивен к реалиям эпохи модерна (когда и произошла его фундаментальная институциализация, и формирование знакомого нам облика). Но данный институт оказался слишком консервативным, неповоротливым, 
негибким и ограниченным в новых, nостмодерных реалиях, предпосылками к постепенному наступлению которых являются технологические факторы (включая глобальную информатизацию, виртуализацию, т.н. NBICконвергенцию, др. феномены) и идеологические сдвиги.

Если рассматривать Постмодерн в качестве перспективного состояния культуры, которое и будет социальным контекстом для дальнейшего развития и функционирования института интеллектуальной собственности, тогда необходимо «примерить» основные признаки постмодерности на исследуемый социальный, культурный и правовой институт.

Это означает, что подобная экстраполяция постмодерных атрибутов на сферу интеллектуальной собственности, вероятно, будет сопровождаться привнесением в самые разные интеллектуально-правовые отношения следующих особенностей: плюрализм (включая и полиморфность), эклектизм (гибридность), агностицизм (моральный релятивизм, который окажет влияние на основы общественной идеологии в отношении «монополии на знания», «дефицита на информацию»), постматериализм, институциональный нигилизм (т.е. утрата прежнего авторитета и расшатывание всей ныне существующей организационно-правовой платформы интеллектуальной собственности).

Хотя говорить о полном демонтаже всей нынешней конструкции исследуемого института было бы слишком самонадеянно. Но что произойдёт непременно, так это его системная трансформация с либеральным оттенком, со смещением в пользу концепций «свободной культуры», «public domain», «открытого контента» и других идей этого же направления, обретающего силу культурного тренда.

\section{References:}

1. Silverman H (1990) Postmodernism: philosophy and the arts / Hugh J. Silverman // New York: Routledge, 1990. - 319 p. (eng).

2. Toynbee A (2006) The study of History: in 3 vol. / Transl., introduction and comments by K. Kozhurin. - St.-Petersburg: Saint-Petersburg State University, 2006. - 1333 p. (rus).

3. Welsch W (1994) Wege aus der Moderne: Schlüsseltexte der Postmoderne-Diskussion / Wolfgang Welsch; Jean Baudrillard. - Berlin: Akademie Verlag, 1994. - 324 p. (ger).

4. Pannwitz R (1917) Die Krisis der europäischen Kultur / Rudolf Pannwitz. - Nürnberg, 1917. 207 p. (ger).

5. Onis F (1934) Antologia de la poesia espanola e hispano-americana 1882-1932 / Federico de Onis. - Madrid, 1934. - 1212 p.

6. Heidegger M (1967) Sein und Zeit / Martin Heidegger. - Tübingen: M. Niemeyer, 1967. 437 p. (ger).

7. Eco U (2002) Zametki na poliakh «Imeni rozy» [Umberto Eco. Postille al Nome della rosa]; transl. by E. Kostiukovich. - Saint-Petersburg: Symposium, 2002. - 91 p. (rus).

8. Eco U (2006) Otkritoe proizvedenie: forma i neopredelenost' v sovremennoi poetike [Eco U. Opera aperta: forma e indeterminazione nelle poetiche contemporanee]; transl. by A. Shurbeleva. - St.-Petersburg: Symposium, 2006. - 408 p. (rus).

9. Eco U (1994) The role of the Reader: explorations in the semiotics of texts / Umberto Eco. - Bloomington, Ind.: Indiana University Press, 1994. - 288 p. (eng).

10. Lyotard J (1984) The postmodern condition: a report on knowledge [Jean-Francois Lyotard. La condition postmoderne]; translated by G. Bennington and B. Massumi; foreword by Fredric Jameson. - Minneapolis: University of Minnesota Press, C1984. - 110 p. (eng).

11. Narizhnyi YA (2008) Filosofiya i kultura epohi postmoderna: Monograph [Narizhnyi Y. Philosophy and Culture of the Postmodern era]. - Dnepropetrovsk: Dnepropetrovsk Humanitarian University, 2008. - 464 p. (rus).

12. Nietzsche F (1985) Götzen-Dämmerung oder Wie man mit dem Hammer philosophiert / Friedrich Wilhelm Nietzsche, 1888. Frankfurt am Main: Insel, 1985. - 123 p. (ger).

13. Hassan I (1987) The postmodern turn: essays in postmodern theory and culture / Ihab Hassan. Columbus: Ohio State University Press, 1987. 267 p. (eng). 